\title{
Shedding light on the epidemiology of gastroesophageal reflux disease in India- a big step forward
}

\author{
Srinivas Gaddam • Prateek Sharma
}

Received: 11 June 2011 / Accepted: 1 July 2011 / Published online: 23 July 2011

(C) Indian Society of Gastroenterology 2011

Gastroesophageal reflux disease (GERD) is defined as a condition which develops when the reflux of stomach contents causes troublesome symptoms and/or complications. It is considered troublesome when mild symptoms occur two or more days a week, or moderate/severe symptoms occur one or more days a week [1]. This global definition underscores the importance of patient symptoms in the diagnosis of GERD.

In western countries, GERD is the most common gastrointestinal disease [2]. It is associated with a huge economic burden and decreased quality of life [3-7]. In addition, GERD can be associated with worrisome complications such as strictures, Barrett's esophagus (BE) and rarely, esophageal adenocarcinoma (EAC) [8]. GERD symptoms occur at least once a month in $44 \%$, once a week in $20 \%$, and daily in $7 \%$ of the adult US population [9-11]. However, studies describing the epidemiology of GERD in India and for that matter in south-east Asia, are sparse and traditionally, GERD is thought to be uncommon in the developing countries [12]. Three important cohort studies published in this issue of the journal, although using slightly varying GERD definitions, draw our attention

S. Gaddam $\cdot$ P. Sharma

Division of Gastroenterology and Hepatology,

Veterans Affairs Medical Center,

Kansas City, MO, USA

\section{P. Sharma}

Division of Gastroenterology and Hepatology,

University of Kansas School of Medicine,

Kansas City, KS, USA

\section{P. Sharma $(\square)$}

Department of Veterans Affairs Medical Center,

4801 E. Linwood Blvd,

Kansas City, MO 64128-2295, USA

e-mail: psharma@kumc.edu to the epidemiology of GERD in India and highlight that its prevalence may be similar to that in western countries.

\section{Prevalence of GERD in India}

The Indian Society of Gastroenterology formed a task force to study the prevalence of GERD and its risk factors. The study by Bhatia et al. [13] is a multi-center prospective questionnaire-based study of 3,224 urban and rural patients and reports the findings of this task force. This study reports a weekly prevalence of $7.6 \%$ in the Indian population. This journal also reports other questionnairebased cross-sectional studies by Sharma et al. and Kumar et al., which also show a high prevalence of GERD (16.2\% to $18.7 \%$ ). In another study, Ramu et al. evaluated the prevalence of GERD in 400 pregnant women and found that the prevalence of GERD in the first trimester was $9.5 \%$, and approximately $50 \%$ during the second and third semesters. The prevalence rate in the first trimester probably reflects the prevalence of GERD in the general population. These studies emphasize that the prevalence of GERD in India is likely to be between $8 \%$ and $19 \%$, which is comparable to GERD prevalence rates published in western countries. Additionally, these studies highlight that the risk factors for GERD are related to diet and lifestyle choice; which are both modifiable risk factors. See Table for a detailed comparison of these studies (Table 1).

\section{Is there a true increase in the prevalence of GERD in India?}

Traditionally, GERD has been thought to be a disease of the western world. Prevalence rates have been estimated to be 
Table 1 Summary of studies evaluating the prevalence of gastroesophageal reflux disease (GERD) in India

\begin{tabular}{|c|c|c|c|c|}
\hline Study & Population & Definition of GERD & Prevalence & Independent risk factors \\
\hline Bhatia et al. [13] & $\begin{array}{l}3,224 \text { urban and rural } \\
\text { adult population }\end{array}$ & $\begin{array}{l}\text { Heartburn and/or regurgitation } \\
\text { at least once a week } \\
\text { for at least } 1 \text { month }\end{array}$ & $7.6 \%$ & $\begin{array}{l}\text { Consumption of } \\
\text { non-vegetarian food }\end{array}$ \\
\hline Sharma et al. [14] & $\begin{array}{l}\text { 4,039 employees of } \\
\text { a tertiary care center }\end{array}$ & $\begin{array}{l}\text { Symptoms score reflecting } \\
\text { severity and duration }\end{array}$ & $16.2 \%^{\mathrm{a}}$ & $\begin{array}{l}\text { Higher BMI } \\
\text { Current smoking } \\
\text { Asthma } \\
\text { Hypertension }\end{array}$ \\
\hline Kumar et al. [15] & $\begin{array}{l}905 \text { urban and rural } \\
\text { adult population }\end{array}$ & $\begin{array}{l}\text { Symptoms score reflecting } \\
\text { severity and duration }\end{array}$ & $18.7 \%^{\mathrm{a}}$ & $\begin{array}{l}\text { Younger age } \\
\text { Sendentary lifestyle } \\
\text { Serum LDL }>150 \mathrm{mg} / \mathrm{dL} \\
\text { High consumption of meat } \\
\text { Low consumption of salted tea } \\
\text { Low consumption of fresh fruits }\end{array}$ \\
\hline Ramu et al. [16] & 400 pregnant women & $\begin{array}{l}\text { Presence of heartburn } \\
\text { and/or regurgitation for } \\
\text { at least a week }\end{array}$ & $\begin{array}{l}\text { First trimester: } 9.5 \% \\
\text { Second trimester: } 43.1 \% \\
\text { Third trimester: } 54.1 \%\end{array}$ & N/A \\
\hline
\end{tabular}

${ }^{\mathrm{a}}$ These studies define GERD using a symptom score based on severity and frequency

lower in Asia when compared to that of the western countries ( $<5 \%$ vs. $10 \%$ to $20 \%$ ) [12]. The current articles on GERD in this Journal [13-16] demonstrate that contrary to previous belief, the prevalence of GERD in India is in fact much higher and similar to that reported in the Western countries. However, it is unclear if this represents a true increase in the prevalence or is the result of a better understanding of the disease symptoms, increased awareness of acid reflux, or the recent conduct of high quality epidemiological studies. In recent years, the progress in the Indian society on both socioeconomic and educational fronts has led to changes in diet and lifestyle choices. This advancement has also resulted in better health education and awareness. Improved knowledge of the disease can result in an increased recognition of GERD; thereby causing an apparent increase in its prevalence. Nonetheless, the impact of adaptation of 'western diet and lifestyle', increasing obesity, reducing $H$. pylori frequency etc. on increase in prevalence of GERD cannot be ruled out.

\section{Challenges with evaluating the epidemiology of GERD in India}

India is a multi-linguistic and multi-cultural society. This can prove to be a challenge when conducting epidemiological studies. English and Hindi are widely spoken in most large cities and metropolitan areas; however, there is a large, significant population that only speaks their local language or dialect. One of the critical difficulties in conducting biomedical research in such a setting is in translating technical English terminology into a local language or dialect. It is likely that some of the words may lose meaning in translation, such that the word-for-word translation may carry a completely different meaning. Thus it is important to meticulously translate terminology and validated questionnaires into the local dialect making sure that the essence of the terminology is not lost in this translation. Furthermore, a consistent definition of GERD has not been widely adopted in studies conducted in India and may also be a challenge in various regions of the country. Since the prevalence of GERD can be profoundly affected based on the definition, for the prevalence rates to be comparable across studies, all future endeavors should use a standardized definition.

\section{Knowledge gaps and future directions}

The estimation of prevalence of GERD in India marks the first step in enhancing our understanding of GERD. Despite the numerous studies on GERD worldwide, there are several gaps in our knowledge of this disease. Future studies on GERD in India should attempt to address several of these gaps while avoiding the pitfalls that have limited the interpretation of the previous studies.

The true population-based prevalence of GERD and risk factors should be assessed. This could lead to the implementation of preventive strategies at the population level that could potentially reduce the burden of GERD in the future. The impact of GERD on quality of life in these patients and whether treatment will lead to improved outcomes should be evaluated. Based on endoscopy, patients with GERD are classified into erosive esophagitis, non-erosive reflux disease or Barrett's esophagus. Future studies should evaluate the prevalence and the longitudinal overlap 
between the various phenotypes of GERD. These findings can have implications on the understanding of mucosal injury and symptoms, and on novel therapeutic interventions to prevent complications. Furthermore, studies should employ physiologic testing such as $\mathrm{pH}$ studies and symptom associated probabilities (assess correlation with symptoms) to improve our understanding of this symptom driven disease.

Although patients with GERD are at a higher risk for BE [17], it is seen that the prevalence of BE is low in India. However, with the new findings of high prevalence of GERD in India, there is a renewed interest in revisiting the prevalence of complications of GERD such as BE and other extra-esophageal manifestations such as the reflux cough syndrome, reflux laryngitis syndrome, reflux asthma syndrome and reflux dental erosion syndrome. Future studies should define the extra-esophageal manifestations of GERD in India.

\section{Conclusions}

Remarkably, very little is known about GERD in India. At this time, one thing is certain - the prevalence of GERD in India is higher than previously estimated and appears to be similar to that of the western countries. Several factors such as increasing obesity, change in diet and lifestyle, smoking, use of specific food types can affect the prevalence of GERD in this rapidly progressing society. With better understanding of the risk factors, it may be possible to target an intervention directed at the main cause of this rapid increase of GERD in India. Furthermore, future studies should perform physiological studies and endoscopically evaluate GERD to gain a better understanding of its cause and complications.

\section{References}

1. Vakil N, van Zanten SV, Kahrilas P, Dent J, Jones R. The Montreal definition and classification of gastroesophageal reflux disease: a global evidence-based consensus. Am J Gastroenterol. 2006;101:190020.

2. Kahrilas PJ. Clinical practice. Gastroesophageal reflux disease. N Eng1 J Med. 2008;359:1700-7.

3. Shaheen NJ, Hansen RA, Morgan DR, et al. The burden of gastrointestinal and liver diseases, 2006. Am J Gastroenterol. 2006;101:2128-38.

4. Wahlqvist P, Reilly MC, Barkun A. Systematic review: the impact of gastro-oesophageal reflux disease on work productivity. Aliment Pharmacol Ther. 2006;24:259-72.

5. Dent J, El-Serag HB, Wallander MA, Johansson S. Epidemiology of gastro-oesophageal reflux disease: a systematic review. Gut. 2005;54:710-7.

6. El-Serag HB. Time trends of gastroesophageal reflux disease: a systematic review. Clin Gastroenterol Hepatol. 2007;5:17-26.

7. Wong BC, Kinoshita Y. Systematic review on epidemiology of gastroesophageal reflux disease in Asia. Clin Gastroenterol Hepatol. 2006;4:398-407.

8. Fennerty MB. The continuum of GERD complications. Cleve Clin J Med. 2003;70 Suppl 5:S33-50.

9. Nebel OT, Fornes MF, Castell DO. Symptomatic gastroesophageal reflux: incidence and precipitating factors. Am J Dig Dis. 1976;21:953-6.

10. A Gallup Organization National Survey: Heartburn Across America. Princeton: The Gallup Organization; 1988.

11. Locke GR 3rd, Talley NJ, Fett SL, Zinsmeister AR, Melton LJ 3rd. Prevalence and clinical spectrum of gastroesophageal reflux: a population-based study in Olmsted County, Minnesota. Gastroenterology. 1997;112:1448-56.

12. Sharma P, Wani S, Romero Y, Johnson D, Hamilton F. Racial and geographic issues in gastroesophageal reflux disease. Am J Gastroenterol. 2008;103:2669-80.

13. Bhatia SJ, Reddy DN, Ghoshal UC, et al. ISG Task Force Report: Epidemiology and symptom profile of gastroesophageal reflux in the Indian population: Report of the Indian Society of Gastroenterology Task Force. Indian J Gastroenterol. 2011;30:doi:10.1007/ s12664-011-0112-x.

14. Sharma PK, Ahuja V, Madan K, Gupta S, Raizada A, Sharma MP. Prevalence, severity, and risk factors of symptomatic gastroesophageal reflux disease among employees of a large hospital in Northern India. Indian J Gastroenterol. 2011;30:doi:10.1007/ s12664-010-0065-5.

15. Kumar S, Sharma S, Norboo T, et al. Population based study to assess prevalence and risk factors of gastroesophageal reflux disease in a high altitude area. Indian J Gastroenterol. 2011;30:doi:10.1007/ s12664-010-0066-4.

16. Ramu B, Mohan P, Rajasekaran MS, Jayanthi V. Prevalence and risk factors for gastroesophageal reflux in pregnancy. Indian $\mathrm{J}$ Gastroenterol. 2011;30:doi:10.1007/s12664-010-0067-3.

17. Sharma P. Clinical practice. Barrett's esophagus. N Engl J Med. 2009;361:2548-56. 